Article

\title{
The Eco-Techno Spectrum: Exploring Knowledge Systems' Challenges in Green Infrastructure Management
}

\author{
A. Marissa Matsler ${ }^{1, *}$, Thaddeus R. Miller ${ }^{2}$ and Peter M. Groffman ${ }^{3,4}$ \\ ${ }^{1}$ Department of Environmental Science and Technology, University of Maryland, College Park, MD 20742, USA; \\ E-Mail: matslerm@umd.edu \\ 2 School of Public Policy, University of Massachusetts, Amherst, MA 01003, USA; E-Mail: thaddeusmill@umass.edu \\ ${ }^{3}$ Advanced Science Research Center at the Graduate Center, City University of New York, New York, NY 10031, USA; \\ E-Mail: pgroffman@gc.cuny.edu \\ ${ }^{4}$ Cary Institute of Ecosystem Studies, Millbrook, NY 12545, USA \\ * Corresponding author
}

Submitted: 20 July 2020 | Accepted: 15 October 2020 | Published: 26 January 2021

\begin{abstract}
Infrastructure crises are not only technical problems for engineers to solve-they also present social, ecological, financial, and political challenges. Addressing infrastructure problems thus requires a robust planning process that includes examination of the social and ecological systems supporting infrastructure, alongside technical systems. An integrative Social, Ecological, and Technological Systems (SETS) analysis of infrastructure solutions can complement the planning process by revealing potential trade-offs that are often overlooked in standard procedures. We explore the interconnected SETS of the infrastructure problem in the US through comparative case studies of green infrastructure (GI) development in Portland and Baltimore. Currently a popular infrastructure solution to a wide variety of urban ills, GI is the use and mimicry of ecological components (e.g., plants) to perform municipal services (e.g., stormwater management). We develop the ecological-technological spectrum-or 'eco-techno spectrum' - as a framing tool to bridge all three SETS dimensions. The eco-techno spectrum becomes a platform to explore the institutional knowledge system dynamics of GI development where social dimensions are organized across ecological and technological aspects of Gl, exposing how governance differs across specific forms of ecological and technological hybridity. In this study, we highlight the knowledge system challenges of urban planning institutions as a key consideration in the realization of innovative infrastructure crisis 'fixes.' Disconnected definition and measurement of Gl emerge as two distinct challenges across the knowledge systems examined. By revealing and discussing these challenges, we can begin to recognize-and better plan for-gaps in municipal planning knowledge systems, promoting decisions that address the roots of infrastructure crises rather than treating only their symptoms.
\end{abstract}

\section{Keywords}

Baltimore; ecosystem services; infrastructure crises; integrated planning; interdisciplinarity; knowledge systems analysis; Portland; science and technology studies; social-ecological-technological systems; water management

\section{Issue}

This article is part of the issue "Urban Planning and Green Infrastructure" edited by Paul Osmond (University of New South Wales, Australia) and Sara Wilkinson (University of Technology Sydney, Australia).

(C) 2021 by the authors; licensee Cogitatio (Lisbon, Portugal). This article is licensed under a Creative Commons Attribution 4.0 International License (CC BY).

\section{Introduction}

The United States (US) has an infrastructure problem. While innovative technological fixes are often the focus of rhetoric around infrastructure solutions, it is important to recognize that each physical break-down-a pothole, leaky pipe, or cracked foundation-is a material manifestation of social-political (as well as technical) 
cause and effect (Grabowski et al., 2017). Therefore, to ' $\mathrm{fix}^{\prime}$ the infrastructure problem in the US, we cannot attend only to physical or technical aspects. We must look to integrated frameworks of infrastructure-such as the social-ecological-technological systems (SETS) framework - to find solutions to chronic breakdowns in service delivery (Markolf et al., 2018).

A SETS framing can integrate municipal institutions and urban planning processes as key facets of the infrastructure problem. A prominent institutional barrier is path dependency: institutions are often unable to easily adjust to new conditions or adopt new solutions that do not fit into fixed institutional approaches and structures (Munoz-Erickson, 2014). For example, stormwater management infrastructure is sized using standardized 'design storms,' which are calibrated to historic storm frequency and intensity. In light of climate change influences on the amount and intensity of precipitation, historic storm data is increasingly insufficient to appropriately size infrastructure (Adams \& Howard, 1986; Watt \& Marsalek, 2013). However, debate regarding the legitimacy of climate science, the obdurate nature of legally binding permitting agreements, and uncertainty regarding which climate projection to use has stalled efforts to update design storms throughout the US (McPhillips, Matsler, Rosenzweig, \& Kim, 2020).

The system of techniques in which municipal institutions gather, vet, use, and circulate different types of information to make decisions can be conceptualized as knowledge systems (Miller \& Munoz-Erickson, 2018). 'Knowledge systems analysis' consists of examining the taken-for-granted procedures and practices institutions use to approach solution development and uncovering the embedded values and visions of how the world works within them (Munoz-Erickson, 2014). Analysis of knowledge systems can help answer underlying interdisciplinary questions related to the US infrastructure problem (Miller, Chester, \& Munoz-Erickson, 2018), including how can we design infrastructure decision-making to integrate social, ecological, and technological solutions to better achieve desired outcomes on-the-ground?

Visions of how the world works impact material reality by constraining the set of solutions we individually or collectively pursue moving forward; this problem-framing necessarily favors some communities and disadvantages others (Bowker \& Star, 1999). Even within seemingly apolitical technical management, social negotiations between worldviews are taking place, embedding certain values into material infrastructures that constrain or ease the actions of our daily lives (Lampland \& Star, 2009). Many of these negotiations are quite mundane, occurring in bureaucratic spaces where experts frame problems and design potential solutions. But the seemingly straight-forward technical nature of these decisions often obscures the fact that they represent political actions (Edwards et al., 2013). Urban planners have long recognized the power inherent in problem-framing, exemplified by an evolution of communicative and participatory planning techniques through time (Carmon \& Fainstein, 2013; Forester, 1982; Healey, 1997). We present knowledge systems and SETS as important tools in the planning toolbox to continue this evolution.

Here, green infrastructure (GI) is a site of inquiry used to explore the knowledge systems influencing infrastructure decision-making in the US today. GI employs directly, or mimics, ecological processes in combination with engineered systems to deliver municipal services, making it an excellent site of explicit intersection between SETS domains. The ecological-technological spectrum of GI-or eco-techno spectrum-is developed as a heuristic to systematically structure an examination of $\mathrm{Gl}$ knowledge system challenges across the three SETS domains. This spectrum highlights the different degrees to which ecological entities (e.g., plants, soils, microbes) are incorporated as infrastructural components in $\mathrm{Gl}$ facilities. This inclusion presents a major social challenge to Gl implementation in that it brings ecological knowledge into traditionally engineering-dominated decisionmaking where it does not easily integrate with established procedures for defining or measuring facilities (Finewood, 2016; Matsler, 2019). The eco-techno spectrum adds needed granularity to research on this system by organizing interdisciplinary connections across specific GI facility types.

In current urban resilience discourse, $\mathrm{Gl}$ is a popular 'fix' for a variety of chronic infrastructure crises (e.g., combined sewer overflows, or CSOs). Therefore, it is important to examine GI facilities holistically as SETS to understand varied potential outcomes/unintended consequences of $\mathrm{Gl}$ programs as they are increasingly deployed across the US. We acknowledge that the SETS framework currently struggles to avoid flattening social systems (as well as ecological and technological systems) to a one-dimensional variable, even though each domain should include a robust range of elements (Figure 1 ; and see Grabowski, Denton, Rozance, Matsler, \& Kidd, 2017, for a critique and expansion of the SETS framework). But we find SETS framing useful in lining up usually disparate disciplinary variables to provide new, if limited, insights.

Here we focus on institutional dynamics as a key social element, which allows us to integrate political, financial, and cultural aspects of Gl; however, we are limited in this work to the point of view of a singular group-institutions. We use the eco-techno spectrum to analyze Gl programs in Portland, Oregon and Baltimore, Maryland and identify the definition and measurement knowledge systems' challenges embedded in municipal institutional dynamics. Our work is, therefore, an analysis of one aspect of the social challenges found across ecological and technological variation. Our results suggest that the eco-techno spectrum can serve as a framework to evaluate the institutional challenges facing innovation in infrastructure management across sectors, including transportation, energy, and water. 


\section{Ecological-Technological Hybridity and the 'Eco-Techno Spectrum' of GI Interventions}

The concept of GI comes with significant conceptual baggage from the differing worldviews that invoke the term to accomplish different goals (Mell \& Clement, 2019). Different stakeholders hold different ideas about both what GI is and what it should do. Conceptual mismatches are exacerbated by the overlap of GI with similar but distinct concepts, such as Nature-Based Solutions and Ecosystem Services (Escobedo, Giannico, Jim, Sanesi, \& Lafortezza, 2019). Differing visions of $\mathrm{Gl}$ are, therefore, contested in US cities attempting to build low-cost and sustainable infrastructures. For example, Finewood (2016) found that Gl options were originally dismissed by engineers in Pittsburgh when completing a new stormwater management plan as knowledge claims regarding Gl's effectiveness were not salient in the established engineering knowledge system. Non-profit and community groups, however, envisioned the social and ecological (beyond the technical) benefits GI could provide and contested the proposed all-grey-infrastructure plan demanding revisions that included $\mathrm{Gl}$.

Here, we develop the eco-techno spectrum as a platform to explore social-political questions of knowledge systems across grounded ecological and technological specifications. In particular, we focus on institutional dynamics as a key social system because there are important institutional barriers that manifest across the variety of facility types that are included in municipal GI programs and plans (Mell, 2013). For example, GI facility types range from small-scale, highly engineered facilities like bioswales and green roofs to large-scale parks, forest patches, and floodplains. In between are urban agriculture facilities, pocket parks, and greenbelts, as well as street tree networks. A primary distinguishing characteristic of $\mathrm{Gl}$ across this variety is the explicit use (or mimicry) of ecological processes to provide utility services; biological elements are integrated to differing degrees with grey technological components to provide services, making GI facilities ecologicaltechnological hybrids used in the service of social systems. This creates issues regarding physical and ecological functionality, but also exacerbates oft-overlooked social-political issues of management; each of these hybrids is managed by different jurisdictions with conflicting goals and missions, complicating the rhetoric of a singular GI program in any municipality. Municipal staff (planners, engineers, accountants, etc.) must navigate this complicated territory to finance, implement, and maintain $\mathrm{Gl}$ systems.

The eco-techno spectrum works to categorize the ecological and technological variety of GI to better organize and specify such social barriers. The spectrum's base highlights the different degrees to which a GI facility includes biological entities (e.g., plants, microbes) as a designed component of the facility they constitute-this is the 'eco' part of the 'eco-techo' shorthand. There is more ecology on the left-hand side of the spectrum and more physical-mechanical technology on right-hand, or 'techno,' side of the spectrum (Figure 1). Other scholars have presented similar spectrums to examine aspects of GI, including Mell's (2013) use of Davies' "grey-green continuum" which highlights distinctions between facilities that are "visually green" (e.g., parks, grass) and those that are considered green because they are "sustainable" (e.g., bike paths, LEED buildings). Bell, Stokes-Draut, and McCray (2018) also propose a gray-green typology focusing more narrowly on stormwater management facilities, while the Royal Society Science Policy Centre's (2014) rejection of a grey or green binary recognizes a "hybrid" category of resilient infrastructure options. Finally, Childers et al. (2019) separates ecotechno hybrids along multiple continuums representing differing ecosystem features, including "blue" (i.e., water-based) and "brown" (i.e., soil-based) infrastructures as well as $\mathrm{Gl}$.

The eco-techno spectrum, therefore, builds on the recognized usefulness of continuums in exposing the ecological and technological nuances of GI efforts. The ecotechno spectrum differs from other efforts by projecting social (the ' $S$ ' in SETS) aspects of infrastructure across this platform. Because of this cross-epistemological framing, the eco-techno spectrum is well suited to explore the connections (and disconnects) between knowledge systems.

\subsection{Operationalizing SETS for GI Research}

The base of the eco-techno spectrum is designed to capture the diversity of technologies, jurisdictions, scales, and ecosystems that make up GI in current municipal programs. Heterogeneity of components, scales, and jurisdictions is not unique to $\mathrm{Gl}$, as nearly all infrastructural systems must cross epistemic and physical boundaries in their organization and management (Pinch, 2010; Star, 1999). However, GI represents a new assemblage of previously disparate groupings and component types which have not been traditionally viewed as 'infrastructure' in urban planning (i.e., plants are not typically viewed as infrastructure). The well-established epistemic categories (Bowker \& Star, 1999) and standards (Lampland \& Star, 2009) that have developed over time in municipal management to deal with cross-boundary issues of grey infrastructure are not germane to managing ecological processes. In fact, in most instances the ecological properties of $\mathrm{Gl}$ are invisible to, or not fungible with, the epistemic community designing, constructing, or maintaining GI (Matsler, 2019). Therefore, understanding and addressing the knowledge systems challenges of $\mathrm{Gl}$ efforts in cities today is critical to the realization of effective service delivery from this infrastructure 'fix.' 


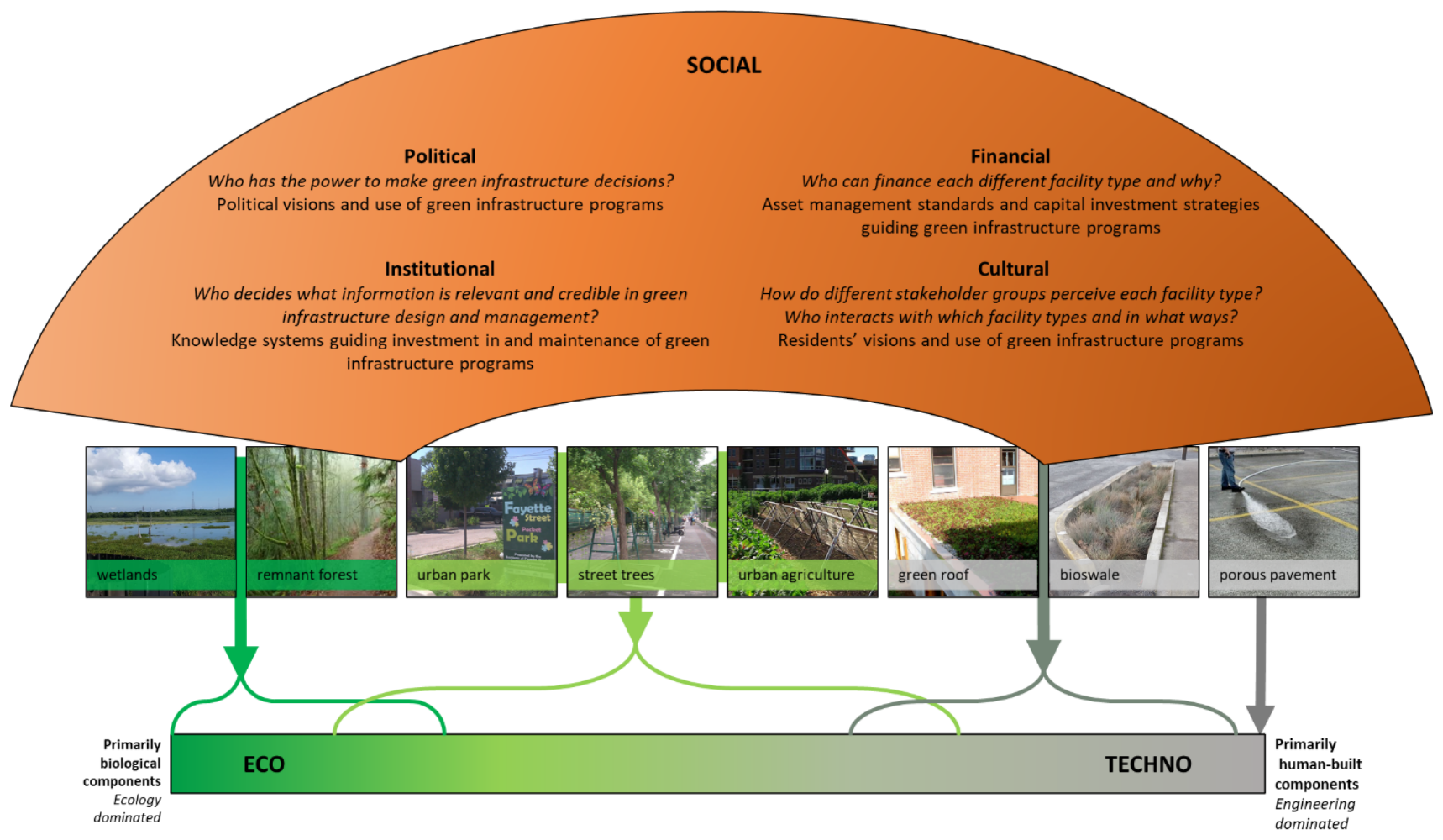

Figure 1. The eco-techno spectrum of $\mathrm{Gl}$ organizes facilities by the proportion of the facility that consists of living, biological components vs. human-made, technological components. This forms a platform on which to connect salient social interactions with ecological and technological parameters, providing a unifying heuristic for operationalizing the SETS framework. The answers to specific social questions differ as one moves from 'eco' to 'techno' facility types, creating diverse social-institutional tensions across spectrum. Notes: Photo credits by Marissa Matsler (wetlands, urban park, street trees, bioswale), City of Portland (remnant forest, green roof), Create Commons (urban agriculture), and Milwaukee Metropolitan Sewerage District (porous pavement). Source: Adapted from McPhillips and Matsler (2018) and Matsler (2019).

\section{Emergent Knowledge System Challenges}

\subsection{Definitional Challenges}

The hybrid make-up of GI facilities does not fit neatly into the jurisdiction of any one municipal department or agency. The divergent goals and missions of these managing authorities has led to differing definitions of GI within cities. Therefore, the development of cohesive city-wide GI strategies (including facility design, implementation, and maintenance standards that work with existing land-use plans) is not straightforward; it requires the reconciliation of multiple knowledge practices across municipal departments.

While the specific definition of GI varies geographically (Mell \& Clement, 2019), it is generally understood to encompass networked greenspaces that provide ecosystem services. Depending on the institution, however, the services and facilities included in the definition of GI can be quite different. For example, Benedict and McMahon's (2006) definition of GI stresses conservation of natural areas: "Green infrastructure is...an interconnected network of green space that conserves natural ecosystem values and functions and provides associated benefits to human populations" (p. 5).
From this perspective, $\mathrm{Gl}$ is a win-win land-use solution with an explicit focus on environmental gains. To the institutions that use this definition, GI represents preserved, conserved, or restored nature.

Alternatively, institutions like the US Environmental Protection Agency (EPA) focus on the stormwater management benefits of $\mathrm{Gl}$ and are often indifferent to the natural character of facilities, allowing engineering solutions to be a major focus of the concept: "Green infrastructure is a cost-effective, resilient approach to managing wet weather impacts that provides many community benefits....At the neighborhood or site scale, stormwater management systems that mimic nature soak up and store water" (EPA, 2015).

Cost-effectiveness and resilience in addressing regulatory compliance issues are unsurprisingly central in definitions from regulatory institutions, with habitat restoration/conservation seen as a co-benefit. Facilities within this framing mimic the functions of natural systems, rather than providing these functions through restoration or conservation of ecosystems. This framing emphasizes technology over ecology.

The eco-techno spectrum helps expose a tension inherent in these differing definitions as each focuses on different facility types: Stormwater management facili- 
ties are nearly all found on the 'techno' side of the spectrum, whereas restoration and conservation facilities are found on the 'eco' side.

\subsection{Measurement Challenges}

GI facilities rely on ecological functions that emerge from the combination of complex and relatively poorlyunderstood biological actors, instead of narrowlydefined and precisely measured physical functions that emerge from the well-understood mechanical components of grey infrastructure. The combination of biological entities in Gl facilities is often novel (Hobbs, Higgs, \& Harris, 2009), meaning existing ecological theory may not apply to the community assembled in a Gl facility. This reliance on unpredictable ecological function makes it difficult to measure or predict the performance of $\mathrm{Gl}$ facilities, complicating estimates of total service delivery.

The challenge of measuring the performance of hybrid systems stems primarily from an epistemological tension. Different epistemic communities measure services in different, sometimes conflicting, ways. An epistemic community is "a network of professionals with recognized expertise and competence in a particular domain and an authoritative claim to policy-relevant knowledge within that domain or issue-area" (Haas, 1992 , p. 3). Engineers represent an epistemic community with a strong 'authoritative claim' over the knowledge relevant to infrastructure performance. This epistemic community does not currently have the tools to fully recognize ecological knowledge in facility performance metrics.

A major challenge in reconciling ecological and engineering epistemic communities arises from the variable and dynamic aspects of ecological systems themselves. Indeed, a major theme in the basic science of ecology over the past 20 years has been a focus on 'disequilibrium' and the 'the flux of nature' rather than earlier ideas about 'equilibrium' and a 'balance of nature' (Wu \& Loucks, 1995). Ideas about stability, resistance, and resilience in ecological systems first emerged in the 1960 s and centered on the ability of these systems to maintain their structure and function in the face of disturbance, or to recover quickly from disturbance (Bormann \& Likens, 1994; Holling, 1973; Odum, 1969). The concept of ecological thresholds, which emerged in the 1970s, is based on the idea that ecosystems can have multiple 'stable' states, depending on environmental conditions (Beisner, Haydon, \& Cuddington, 2003; Holling, 1973).

While ideas about stability and resilience have helped environmental scientists to conceptualize ecosystem dynamics, they have been difficult to operationalize and use in practical management of actual environments (Groffman et al., 2006). Current active areas of research include developing an ability to monitor and predict where and when state changes are likely to occur, how to manage for resilience, and how to reverse state changes. There is a clear need to resolve these issues within the epistemic community of ecology before these concepts can be used to design and implement $\mathrm{Gl}$.

\section{Methods}

We examined the various perspectives of GI (what it is and what it should do) at work in municipal administrative structures of ongoing $\mathrm{Gl}$ planning and implementation in Baltimore, Maryland and Portland, Oregon to reveal current knowledge systems' challenges. Comparative case study methods were used-following Yin (2014)-from 2015 to 2017. Important contextual differences between the two cities, including their socioeconomic make-up, racial identity, and regulatory environment make them ripe for comparison (Table 1). Results presented in this paper were derived from semi-structured interviews conducted with professionals involved in the planning, construction, financing, and maintenance of $\mathrm{Gl}$ programs in each city. These professionals represented a range of disciplinary backgrounds and administrative roles (Table 2). A total of 42 interviews were conducted: 22 in Portland and 20 in Baltimore. Because the primary focus of this work is knowledge systems of municipal government institutions, most interviews were done with city staff from various departments. However, in Baltimore, it was necessary to expand interviews outside of city staff because most GI implementation was conducted by NGOs at the time of data collection. In every interview conducted with municipal staff in Baltimore at least one non-profit (and usually upwards of three) was mentioned as an instigator, an implementer, or a partner in GI development; therefore, we were confident in including multiple interviews with NGO staff in Baltimore. In contrast, most design, implementation, and maintenance of $\mathrm{Gl}$ facilities, and the knowledge production supporting those actions, was found in-house at the City of Portland; private firms and NGOs were not mentioned in interviews. Therefore, though some conversations occurred with private consultants and non-profit staff in Portland, we were confident confining formal interviews to city staff. Recorded interview audio was transcribed by a third-party service. Transcripts were analyzed using ATLAS.ti following Friese's $(2014,2016)$ coding techniques. Discourse analysis was employed to categorize and interpret results (Hajer \& Versteeg, 2005).

Interviews were chosen as the primary data collection method in this study because of their ability to provide robust descriptive data regarding how knowledge systems around Gl work in situ, something that document analysis alone cannot reveal. As a relatively newly recognized infrastructural system, institutional dynamics of $\mathrm{Gl}$ are emergent and therefore well-suited to inductive methods, rather than deductive methods that help refine and/or challenge already defined systems. Interviews, however, have limitations. While interview subjects can provide perspectives on their organizations and social networks, the data gathered is limited to the perspective 
Table 1. Case study SETS characteristics, highlighting two long-term GI programs in different social, ecological, and technical contexts.

\begin{tabular}{|c|c|c|}
\hline Context & Baltimore & Portland \\
\hline \multicolumn{3}{|l|}{ Social } \\
\hline Population (2017) & 610,481 & 647,924 \\
\hline African American & $63 \%$ & $6 \%$ \\
\hline White & $31 \%$ & $76 \%$ \\
\hline Median Income (2017) & $\$ 47,131$ & $\$ 63,974$ \\
\hline Growth & $\begin{array}{l}\text { Shrinking, currently plateauing city } \\
\text { with large amt of vacant and } \\
\text { abandoned lots }\end{array}$ & $\begin{array}{l}\text { Growing city with increasing } \\
\text { housing market pricing out } \\
\text { many residents }\end{array}$ \\
\hline Governance & $\begin{array}{l}\text { Strong-mayor, Mayor-Council } \\
\text { Form Government }\end{array}$ & $\begin{array}{l}\text { Weak-mayor, Commission Form } \\
\text { Government }\end{array}$ \\
\hline Equity \& Justice & $\begin{array}{l}\text { High poverty rates and racial } \\
\text { segregation }\end{array}$ & $\begin{array}{l}\text { Large and growing homeless } \\
\text { population }\end{array}$ \\
\hline \multicolumn{3}{|l|}{ Technology } \\
\hline Sewer system & Separated storm and sanitary sewer & $\begin{array}{l}\text { Combined storm and sanitary sewer } \\
\text { (some areas separated sewer) }\end{array}$ \\
\hline \multicolumn{3}{|l|}{ Regulations } \\
\hline $\begin{array}{l}\text { National Pollutant Discharge Elimination } \\
\text { System (NPDES) Permit }\end{array}$ & MS4 \& SSO program & MS4 \& CSO program \\
\hline EPA Consent Decree & 2002 & 1991 \\
\hline Total Maximum Daily Load (TMDL) & $\begin{array}{l}\text { Trash, Nitrogen, Total Suspended } \\
\text { Solids }\end{array}$ & Phosphorus, Total Suspended Solids \\
\hline \multicolumn{3}{|l|}{ Ecological } \\
\hline Avg precipitation & $41.9^{\prime \prime}$ in 116 days & $43.5^{\prime \prime}$ in 164 days \\
\hline Rainfall patterns & $\begin{array}{l}\text { Short, intense } \\
\text { rainstorms/thunderstorms }\end{array}$ & Continuous, low intensity rainfall \\
\hline Urban tree canopy cover (2018) & $27.4 \%$ & $29.9 \%$ \\
\hline ParkScore Ranking (2020) & 58/100 Largest US Cities & 6/100 Largest US Cities \\
\hline Biome & Temperate Forest & Boreal Forest \\
\hline
\end{tabular}

Notes: Population and Median Income estimates from US Census Bureau $(2017,2019)$. Urban Tree Canopy estimates in Portland from Ramsey and DiSalvo (2018) and Baltimore from Department of Recreation \& Parks (2018). ParkScore ranking from Trust for Public Land (2020).

Table 2. Breakdown of interviewees by city and professional role.

\begin{tabular}{lcc}
\hline Participant Professional Role & Baltimore & Portland \\
\hline Environmental Science \& Management & 5 & 7 \\
Finance/Accounting & 2 & 7 \\
Engineering & 4 & 3 \\
Landscape Architecture & 2 & 1 \\
Planning & 3 & 2 \\
Administration/Project Management & 3 & 1 \\
Public Outreach & 1 & 1 \\
Total \# of Participants & 20 & 22 \\
\hline
\end{tabular}


of the subject pool. We attempt to mitigate this by identifying a broad group of practitioners across Portland and Baltimore to confirm agreement and overlap on approaches and processes, though we acknowledge that some bias still exists. Future GI knowledge systems work should expand datasets to include additional methods, such as surveys (for example, social network analysis of institutional actors), as well as work to include the perspectives of residents and community groups.

\section{Case Study Results}

\subsection{Definitional Knowledge System Challenges}

All interviewees were asked: "What is your working definition of GI?" There were two generally agreed upon aspects across all interviewees in both cities. First, GI facilities include living components (not just 'sustainable' components):

I think anything that's just planted with vegetation, whether it's native or nonnative vegetation, and something that's a dynamic system that is managed as such. (Portland, Bureau of Environmental Services [BES] staff)

To me, green infrastructure is natural. It's...trees, vegetation; especially when that's replacing impervious concrete and grey infrastructure..... It's green because it's a natural feature, like a native plant. It is based on a living organism and a local ecosystem. (Baltimore, non-profit staff)

But it was also clear that the urban nature that makes up $\mathrm{Gl}$ is not just any nature. GI refers to nature that provides services; this type of nature was what made it 'infrastructure':

It is natural systems that are being used to support services that we provide. (Portland, Office of Management and Finance [OMF] staff)

Anything that you could provide traditionally in a built way that you're instead providing in a green type of way. (Baltimore, Office of Sustainability staff)

Personally, I was interested in using soil and plants to slow down the runoff, to filter the runoff, and to try to infiltrate and remove as much of the runoff, as close to its source as possible. I think that's pretty close to our official definition. (Portland, BES staff)

Streams, trees, green roofs. I think about everything about dealing with surface water. (Baltimore, Department of Public Works [DPW] staff)

Second, GI was overwhelmingly defined as multifunctional, providing a wide range of co-benefits includ- ing urban heat island mitigation, stormwater management, air purification, water treatment, biodiversity, traffic calming, habitat, social cohesion, and more. This was summed up succinctly by a Baltimore DPW staffer who responded "oh everything" when asked what services are provided by GI.

However, beyond these two nodes of agreement, there was significant differentiation in the definition of GI. Definitions were more strongly differentiated across departments/institutions within each city than between cities. For example, both Baltimore Recreation and Parks Department and Portland Bureau of Parks and Recreation focused on an expanded network view of GI which included forest patches and natural areas as facility types; these are facilities found on the 'eco' side of the eco-techno spectrum. In contrast, utility departments like BES and DPW focused instead on modular stormwater management facilities (e.g., bioswales) found on the 'techno' side of the spectrum.

The eco-techno spectrum therefore points out that problem-framing differs across departments within a city, rather than between cities; this suggests that technological and ecological differences between the cities (e.g., combined vs. separated sewers) are not driving problem-framing as much as the jurisdictional mandate for specific departments to provide specific services (i.e., the demand for stormwater management and recreation services more generally in each city). This highlights the importance of socio-institutional aspects of GI service delivery to GI program development.

\subsubsection{Challenge or Opportunity?}

Another differentiation between municipal departments in both cities was their response to the broadness and ambiguity of $\mathrm{Gl}$ as a term. A quote from a staffer at the Baltimore Recreation and Parks Department sums up the overarching sentiment: "It's such a broad term, I mean, I don't think I've ever heard a textbook definition that everyone has agreed upon." The definitions provided by other interviewees reflected this broadness, describing a range of facilities that span the eco-techno spectrum.

The broadness of GI definitions was described alternately as a positive or a negative feature. Sentiments towards definitional broadness differed by department and organization type, not by city. For example, staff at DPW expressed concern over the implications of definitional ambiguity for the stormwater management budget:

We focus on [stormwater] because, when it becomes too broad, green infrastructure suddenly becomes greening. Suddenly it becomes let's spend DPW stormwater fee utility money...to do community gardens...[or] any number of things that really have little to no benefit for stormwater. So we have to be very careful using the terminology and managing our funds....There are people within city government and 
outside city government that feel like "oh, we have now this pot of money that we can use for any type of greening" and...we can't because our goal is to meet the MS4 [municipal separate storm sewer system] permit. (Baltimore, DPW staff)

However, other interviewees saw the broadness of the term in a positive light. Staff in coordinating departments and agencies such as the Portland Bureau of Planning and Sustainability and the Baltimore Office of Sustainability expressed that they were encouraged by the "wiggle room" available from ambiguity; it allowed them to connect more stakeholders to projects. This difference in views of specificity represents a knowledge system challenge. One department 'knows' infrastructure within narrow physical and economic tolerances that must be met for appropriate and legal function; it has knowledge practices (for example protocols for quantifying stormwater run-off) that fit a single-service, 'techno' infrastructure vision. Other departments 'know' infrastructure as something that must accommodate a wide range of community needs; they have knowledge practices (for example norms of inclusivity and protocols for gathering multiple qualitative points of view at public outreach events) that fit a wider, multiple-benefit, 'eco' infrastructure vision. This contrast in knowledge practices is common within cities (Friedmann, 1993), but here presents novel challenges.

An additional challenge, expressed across all groups, was the lack of understanding or definition of GI facilities as actual 'infrastructure' by city residents and property owners. In Baltimore, it was challenging for facility inspectors to keep up with new property owners:
People don't even know what they have. With green infrastructure in particular, they look at it and all they see is "I've got a garden. If I let the weeds grow in the garden, so what?" They don't know what they're supposed to do....We find a lot of times our inspections are re-informing the property owners of what they're supposed to do. (Baltimore, DPW staff)

In Portland, BES faced a lawsuit in 2014 from ratepayers arguing that GI was part of "mission creep" within the bureau. They called spending on green streets (a GI facility type) a "misappropriation of sewer funds" spent on "luxury greening projects" rather than 'real' sewer projects (Law 2014), displaying the lack of recognition of $\mathrm{Gl}$ as 'infrastructure' on the part of plaintiffs.

In summary, we found that definitions differed most between departments within cities. The ambiguity around GI produced legal and budgeting challenges for engineering-based departments while a broad definition was a boon to Planning and Parks departments in both cities. When we project these findings onto the eco-techno spectrum (Figure 2), we can begin to relate specific facility types with different definitions of $\mathrm{GI}$. Misinterpretations of the term by those with alternate definitions of GI can lead departments to act like "ships in the night" (Vogt, 2018), missing opportunities to provide more effective service delivery and outreach, when facility types are left implicit in planning efforts.

\subsection{Measurement Knowledge System Challenges}

Accurate performance metrics are important to infrastructure management. However, it was apparent from

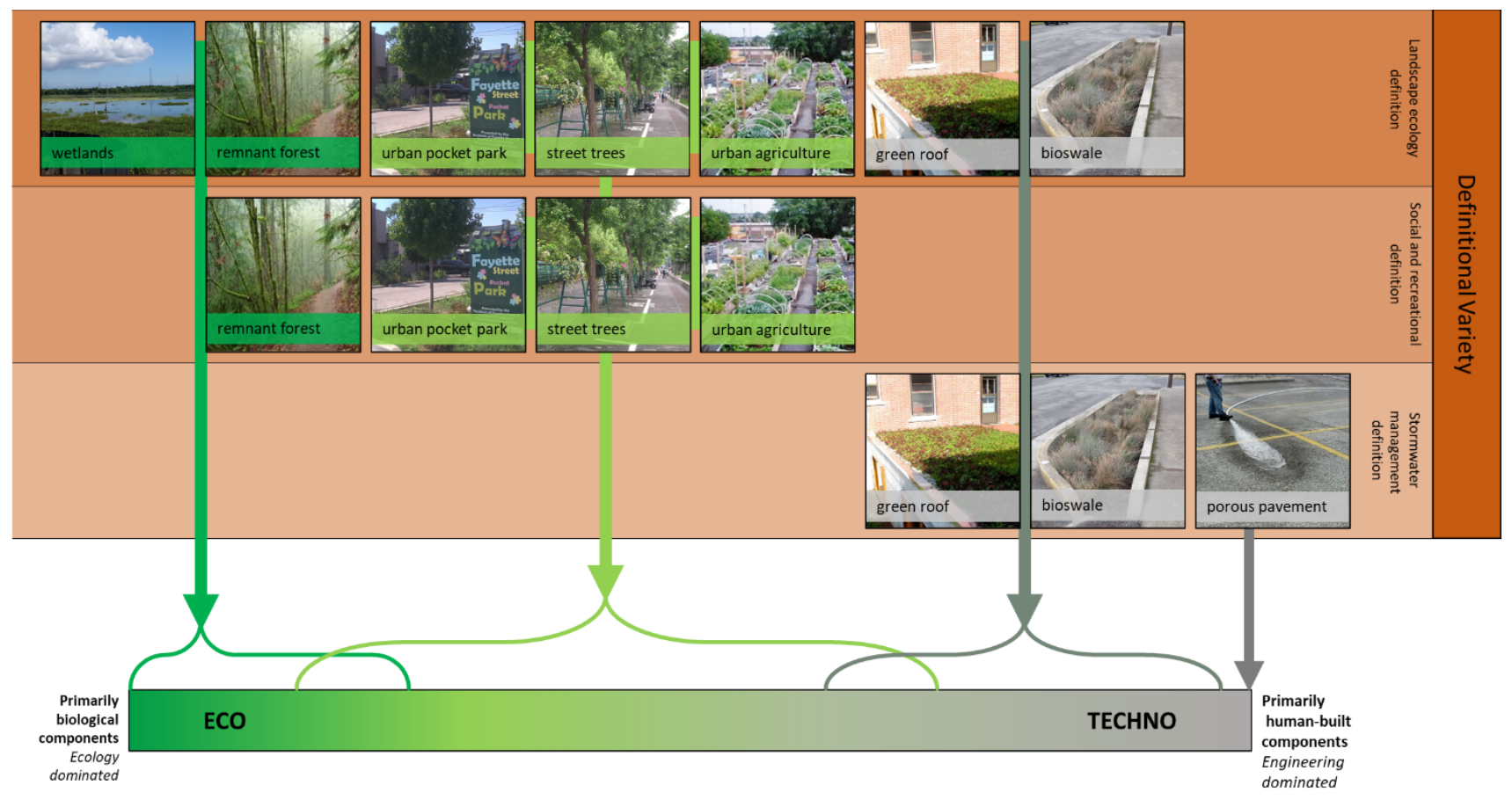

Figure 2. Facility types most commonly associated with, but usually implicitly, three distinct definitions of GI. 
interviews that performance metrics were influenced by definitions of $\mathrm{Gl}$ and the mission of the institution implementing the facility. Here, particular attention was given to assessment of biological entities in GI facilities. Plants used within facilities are often described as having little or no influence on the hydrologic functionality of a facility. A more nuanced understanding of this view came out in interviews: While all interviewees in this study perceived plants as having a role in facility function, none knew of metrics that were regularly employed to assess that functionality. As one engineer described it, it depended on what service was being measured:

You could easily support that idea [that the plants are only 'window-dressing'] by picking one of those analytes out. Like if you said, hey, let's focus on the metals or the solids or something, maybe the plants aren't that critical because it's really the media, or it's that filter, that's stopping that material from reaching...the creek or to the street storm sewer. However, they [the plants] reduce the heat island effect, they help temperature, they help uptake of certain other things like nitrates...oils and greases tend to get trapped in vegetation at a certain rate....So, it depends on what you're talking about. (Portland, BES staff)

In both Baltimore and Portland water quantity and quality were highlighted in the discussion of measurement. Nearly all regulatory requirements revolved around these metrics, making them the most discussed and most well-developed measurements across all groups:

It's all rooted in hydrology. So, it's looking at here's what a site would look like hydrologically if it was all wooded and forested. And then your objective is to build buildings on it but mimic that natural hydrograph. So as long as you can do it, you can fit as many buildings on there as you want, as many roads, if you can capture and treat the run off and mimic that natural hydrograph, then the State would give you a check mark, you have done your job. (Baltimore, private firm staff)

[Water] quantity is a real important aspect and benefit of green infrastructure...and that's what the manual is designed [for]. There's other benefits to green infrastructure, that's recognized, but that's not the driver for us as far as requiring green infrastructure. (Portland, BES staff)

The focus on water quantity and quality has meant that less attention has been given to other services (like biodiversity, social cohesion, air quality improvements, wellbeing, etc.). These other services were discussed by interviewees (and are often touted by GI advocates in general) as important co-benefits of $\mathrm{Gl}$; but actual mechanisms to integrate these services into level-of-service or performance metrics was not reported in either city. Delivery of such services was mostly assumed by interviewees based on studies indicating the potential for GI to provide these services.

Again, when we project these findings onto the ecotechno spectrum (Figure 3), we can relate different metrics with different facility types (i.e., different ecological and technological parameters). As discussed in the background, metrics evaluating ecological functions of GI facilities are currently imprecise while hydrologic functions are well known. Primarily, hydrologic functions are used as metrics for 'techno' facilities and we can see that as we move toward 'eco' facilities that less precise ecological metrics dominate. This projection therefore begins to show potential differentiation within the suite of services provided across the concept of $\mathrm{Gl}$; there is a need to address and plan for such variation, rather than lumping all GI into a singular concept.

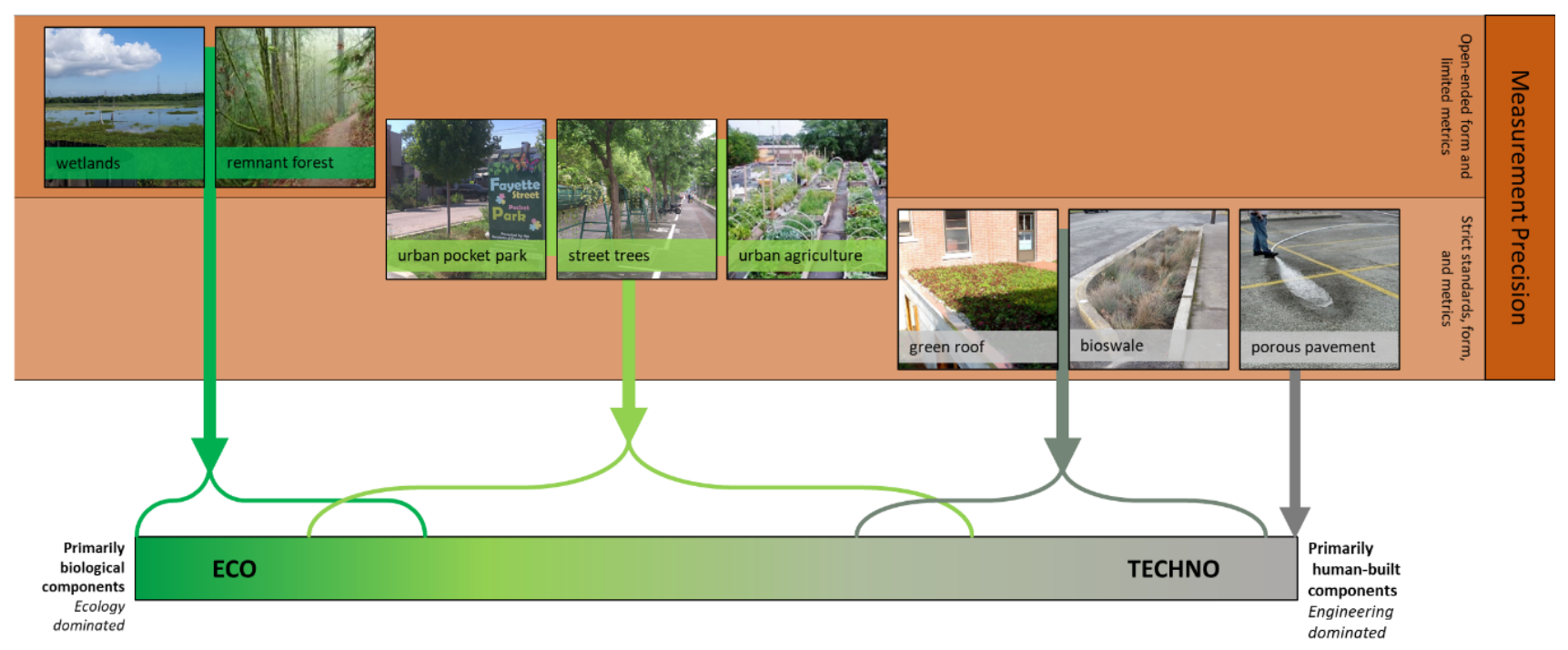

Figure 3. Precision and focus of metrics and standards vary across the eco-techno spectrum. 


\subsubsection{Emergent Work-Arounds?}

To work around measurement challenges, interviewees described institutional changes and adjustments that were primarily focused within a department/bureau. Performance metrics are tied closely to the mission and public obligation of each department (i.e., CSO reductions by BES, or recreation obligations of the Baltimore Recreation and Parks Department) and must reflect the progress that the institution is making towards its level-of-service goals. This contrasts with the definitional challenges and changes discussed above which are mostly in regards to communication across departments and communities.

First, both cities mentioned the extended use of asset management software to track GI facility performance through time. Initially, GI facilities were not included in BES or DPW's databases. At BES, as the number of curb side bioswales grew over time, they were added to the database, but the biological aspects of the facilities were not included. Staff now say that more detailed information regarding the condition of these biological entities is being tracked via their asset management software and that this tracking has become more granular:

It used to be that, if they went up to do maintenance, and that was a project that had...20 Green Streets [bioswales], they would all be lumped into one entry.....Now they're able to actually pinpoint: "Well, 18 of those 20 facilities were easy, and these 2 here were the hard ones, that had a lot of sediment, or had problems with plant coverage," or what have you. It allows us to look a little more closely at patterns and maintenance activity, and that's certainly a new focus. (Portland BES staff)

Increased tracking of maintenance activities and facility condition will ultimately feedback into the design and implementation of GI in Portland, making the selection of what to measure an important decision point in this knowledge system. It is important to note that the generation of new software is ideally a linear process that follows the definition of needed functions and the development of indicators of those functions. However, municipal practice is far from ideal and this example highlights how the use of software can evolve in practice.

In Baltimore, a measurement challenge emerged from projects built by non-profits that did not have "asbuilt" documents. In order for a GI facility to count towards fulfilling the city's regulatory commitments of their MS4 permit, it needs to be assessed by an engineer as it is being built to determine how closely the designs for the facility match what is actually built on-theground. Without this documentation, non-profits were building projects that were not fungible with city government knowledge systems.

To address this measurement challenge, a collaborative process has begun in Baltimore where non-profits work directly with funders to earmark funds for the completion of as-built documents, and DPW contributes funds to retroactively commission as-built documents on some existing facilities. In this way, DPW can use these facilities in meeting the city's MS4 permit:

[The State of Maryland Department of Natural Resources] was not providing funding for a group like Parks \& People [a local Baltimore non-profit] to do an as-built, so we all got together and said: "There's this disconnect, right?" (Baltimore DPW staff)

If you want to meet the intent of the money you need to include funding for as-builts so they can be transferred to the city as credits. So facilities that have already been put in...now we are developing a MOU [memorandum of understanding] with the City, for projects that you can go back and say "Yes, this is the project that happened." (Baltimore, non-profit staff)

Both non-profit and the city staff expressed relief that this process was moving forward. The tension between the institutions' knowledge systems is gradually easing as they find ways to mutually support one another in Gl development: "We are in the process of going through...[and] transferring credit to the city. It makes you feel good that you are making change" (Baltimore, non-profit staff).

\section{Discussion}

\subsection{Competing Visions}

When examining GI definitions in Baltimore and Portland, we found evidence for the use of both greenspacenetwork (Benedict \& McMahon, 2006) and stormwaterfocused (EPA, 2015) visions. While a dominate vision was not detected in either city, it does appear that these two visions integrate and compete in different ways in the two contexts. Parsing out these visions across degrees of ecological and technological hybridity along the ecotechno spectrum allowed us to see which definitions and metrics are most likely to encourage different facility types or services, differentiation that is usually implicit in planning for $\mathrm{Gl}$ as a whole in cities. By adding this granularity, we can begin to make explicit the embedded assumptions about facility types and the services they provide in planning processes; this mitigates confusion and unmet promises of incorrect assumptions.

Primarily, we observed knowledge practices dictated by regulations influencing the interplay of GI visions. In Portland, a federal mandate to address CSO violations was the initial driver of Gl development. Because this required managing water quantity (i.e., keeping stormwater out of the combined sewer system), a stormwater-focused way of knowing $\mathrm{Gl}$ emerged in Portland. Without a CSO regulatory push, Baltimore's primary driver was Chesapeake Bay-wide efforts to address 
water quality issues. Baltimore's MS4 permit and TMDL challenges have motivated solutions focused on forest patch enhancement and restoration where impervious surface is removed to restore natural hydrologic regimes. The facility types encouraged by this type of regulation are more easily integrated in a larger, regional green network vision of GI. However, facilities from across the ecotechno spectrum are built in both cities, showing that the negotiation of definitional and measurement contestations regarding $\mathrm{Gl}$ does not result in uniform adoption of one vision or the other.

In both cities, technological differences initially appear to have the most influence on $\mathrm{Gl}$ investments and definitions. The presence of separated (Baltimore) or combined (Portland) sewer systems dictated the type and severity of the regulatory violations in each city, driving the adoption of different types of infrastructure 'fixes.' But, parsing groups within each city, we find that municipal knowledge systems show differentiation within, or in spite of, this overarching regulatory framework. The tensions between the knowledge systems of engineering, parks/recreation, utility, and planning departments were often more important than technological differences.

Why is it important to understand what and how visions dominate in a city? The knowledge practices that support more 'eco' facilities or more 'techno' facilities to be built create new barriers to specific ecosystem services and to the equitable distribution of such services. For example, stormwater problem-framing of 'techno' facilities amplifies water quantity and quality management functions at the expense of other important benefits like nutrient cycling, recreation, or air filtration, among many others. This seemingly apolitical technical decision can cause very real social consequences by precluding the provision of other important services on-theground. As Bowker and Star (1999, pp. 5-6) put it: "Each standard and each category" - understood as knowledge systems' practices in this study - "valorizes some point of view and silences another." We need to be explicit about what and who is being silenced by current stormwaterfocused Gl planning.

\subsection{Interactions across the Eco-Techno Spectrum}

GI facility types that span the entire eco-techno spectrum are present in both cities. While not every city department, non-profit, or company recognizes the entire spectrum as $\mathrm{GI}$, all points along it are recognized by at least one institution in each city. It is important to reiterate here that each definition of GI seems to point towards a different end of the eco-techno spectrum. While $\mathrm{Gl}$ is often described in policy and outreach as a singular concept, there is significant variability regarding the services provided by 'eco' vs. 'techno' facilities. This is most apparent when looking at the extremes of the spectrum: Porous pavement is Gl because it mimics natural hydrology and provides water infiltration ser- vices, but it would be strange to attribute spiritual or cultural values of nature more generally to the parking lots and driveways that it creates. As one moves along the eco-techno spectrum away from porous pavement and towards 'eco' facilities like forest patches, the number and scope of services provided can increase; but service delivery depends on initial design parameters, as well as ongoing maintenance activities. The eco-techno spectrum organizes these differences more systematically than a simple 'grey' vs. 'green' infrastructure dichotomy. While 'grey' vs. 'green' was an important starting point, we now need greater granularity to effectively plan GI systems. The eco-techno spectrum, and frameworks like it, begin to do this work.

Institutionally, it is useful to note that protocols stemming from regulatory structure and norms inherent in economic status were observed differentiating whether an institution opted to build more 'techno' or more 'eco' leaning facilities. For example, Baltimore faces budget shortfalls. While cheaper than many grey infrastructure systems, GI facilities on the 'techno' side of the eco-techno spectrum are still expensive. Without a regulatory push demanding money be spent on this problem, the knowledge claims indicating the multiple benefits of most 'techno' GI solutions do not sway a cost-benefit analysis to justify their implementation in Baltimore. In fact, Portland BES is now dealing with a similar issue as they turn their concentration from CSO watersheds to MS4 watersheds:

Now that we've done the first phase of our combined sewer work...we've started to put more attention into the separated parts for our system, the MS4 system....The questions become a little more difficult, it's not quite as easy to do an apples to apples comparison of grey and green anymore. If you're dealing with water quality issues, how much did you spend to remove a pound of total suspended solids out of the system? Those questions aren't quite so clear-cut. (Portland, BES staff)

As this turn has progressed, institutional norms in Portland have moved towards an integration of facilities across the eco-techno spectrum, with a focus on more comprehensive planning integrating both stormwater and network visions:

I call what we do, little 'g,' little 'I,' green infrastructure, and then there's capital 'G,' capital 'I,' Green Infrastructure, which would include all of the interconnected, larger ecosystem type things that come in, so really our forests, and then natural areas and stream corridors that we still have that need to be protected, and interconnect those things. (Portland BES staff)

By looking across the challenges highlighted by the ecotechno spectrum, Portland's movement towards integration can be expected to present new barriers and con- 
cerns to GI planning. Standards and prescriptive codes are likely necessary for 'techno' facilities, however this will limit development of 'eco' facility types that lack metrics and are not normally included in stormwater management definitions. Awareness of this inertia towards uneven development across the eco-techno spectrum can focus planning processes on rebalancing effort to be sure a full spectrum of greenspace facilities are built, conserved, and maintained to ensure all expected services are provided by the Gl system.

\section{Conclusion}

Municipalities are increasingly looking towards GI to sustainably 'fix' a wide variety of infrastructure crises they face. However, this research has shown that GI planning runs into institutional challenges that limit its ability to provide needed benefits. Gl efforts in both Portland, Oregon and Baltimore, Maryland provide examples of knowledge systems' challenges faced by urban planning processes attempting to integrate GI. Our results suggest that viewing $\mathrm{GI}$ facilities along an eco-techno spectrum helps to make explicit the different plans for, and outcomes of, these facilities across usually siloed epistemic communities. By adding granularity and specificity to the SETS relationships across different forms of $\mathrm{GI}$, the eco-techno spectrum can help municipal actors and researchers better recognize and account for the multi-functional nature of GI. This can lead to better articulation of the financial and institutional responsibilities of different GI approaches and help municipalities choose the most appropriate facility types to do the job they need.

GI facilities explicitly integrate ecology and engineering in their design, but arguably all infrastructures can be viewed as eco-techno hybrids. By projecting social, cultural, political, financial, and institutional factors onto a more granular set of ecological and technological parameters (rather than a simple grey-green dichotomy), we begin to see more explicit differences in service delivery from infrastructural systems built using different problem frames and visions. Revealing and acknowledging these differences is a concrete step towards planning more effective GI programs specifically and more robust infrastructure crisis 'fixes' in general.

\section{Acknowledgments}

We would like to acknowledge and thank practitioners in Portland and Baltimore for sharing their time and expertise with us, providing deep insights to this work. This material is based upon work supported by National Science Foundation IGERT Grant \#0966376: "Sustaining Ecosystem Services to Support Rapidly Urbanizing Areas." Any opinions, findings, and conclusions or recommendations expressed in this material are those of the authors and do not necessarily reflect the views of the National Science Foundation.

\section{Conflict of Interests}

The authors declare no conflict of interests.

\section{References}

Adams, B. J., \& Howard, C. D. D. (1986). Design storm pathology. Canadian Water Resources Journal, 11(3), 49-55.

Beisner, B., Haydon, D., \& Cuddington, K. (2003). Alternative stable states in ecology. Frontiers in Ecology and the Environment, 1(7), 376-382.

Bell, C. D., Stokes-Draut, J., \& McCray, J. E. (2018). Decision making on the gray-green stormwater infrastructure continuum. Journal of Sustainable Water Built Environment, 5(1).

Benedict, M. A., \& McMahon, E. (2006). Green infrastructure: Linking landscapes and communities. Washington, DC: Island Press.

Bormann, F. H., \& Likens, G. E. (1994). Pattern and process in a forested ecosystem: Disturbance, development and the steady state based on the Hubbard Brook ecosystem study. Cham: Springer.

Bowker, G. C., \& Star, S. L. (1999). Sorting things out: Classification and its consequences. Cambridge, MA: MIT Press.

Carmon, N., \& Fainstein, S. S. (Eds.). (2013). Policy, planning, and people: Promoting justice in urban development (1st ed.). Philadelphia, PA: University of Pennsylvania Press.

Childers, D. L., Bois, P., Hartnett, H. E., McPhearson, T., Metson, G. S., \& Sanchez, C. A. (2019). Urban ecological infrastructure: An inclusive concept for the non-built urban environment. Elementa: Science of the Anthropocene, 7(1), http://doi.org/10.1525/ elementa.385

Department of Recreation \& Parks. (2018). What is the Tree Canopy. Baltimore City. Retrieved from https://bcrp.baltimorecity.gov/forestry/ treebaltimore/canopy

Edwards, P. N., Jackson, S. J., Chalmers, M. K., Bowker, G. C., Borgman, C. L., Ribes, D., . . . Calvert, S. (2013). Knowledge infrastructures: Intellectual frameworks and research challenges (Working Paper No. 2013-05). Ann Arbor, MI: University of Michigan. Retrieved from http://deepblue.lib.umich.edu/ handle/2027.42/97552

Environmental Protection Agency. (2015). What is green infrastructure? EPA. Retrieved from http:// www2.epa.gov/green-infrastructure/what-greeninfrastructure

Escobedo, F. J., Giannico, V., Jim, C. Y., Sanesi, G., \& Lafortezza, R. (2019). Urban forests, ecosystem services, green infrastructure and nature-based solutions: Nexus or evolving metaphors? Urban Forestry \& Urban Greening, 37, 3-12.

Finewood, M. H. (2016). Green infrastructure, grey epistemologies, and the urban political ecology of Pitts- 
burgh's water governance: Pittsburgh's water governance. Antipode, 48(4), 1000-1021.

Forester, J. (1982). Planning in the face of power. Journal of the American Planning Association, 48(1), 67-80.

Friedmann, J. (1993). Toward a non-Euclidian mode of planning. Journal of the American Planning Association, 59(4), 482-485.

Friese, S. (2014). Qualitative data analysis with ATLAS.ti (2nd ed.). Los Angeles, CA: SAGE.

Friese, S. (2016). CAQDAS and grounded theory analysis (MMG Working Paper No. 16-07). Berlin: Max Planck Institute.

Grabowski, Z. J., Denton, A., Rozance, M. A., Matsler, M., \& Kidd, S. (2017). Removing dams, constructing science: Coproduction of undammed riverscapes by politics, finance, environment, society and technology. Water Alternatives, 10(3), 769-795.

Grabowski, Z. J., Matsler, A. M., Thiel, C., McPhillips, L., Hum, R., Bradshaw, A., . . . Redman, C. L. (2017). Infrastructures as socio-eco-technical systems: Five considerations for interdisciplinary dialogue. Journal of Infrastructure Systems, 23(4).

Groffman, P. M., Baron, J. S., Blett, T., Gold, A. J., Goodman, I., Gunderson, L. H., ... Wiens, J. (2006). Ecological thresholds: The key to successful environmental management or an important concept with no practical application? Ecosystems, 9(1), 1-13.

Haas, P. (1992). Epistemic communities and international policy coordination. International Organization, 46(1), 1-35.

Hajer, M., \& Versteeg, W. (2005). A decade of discourse analysis of environmental politics: Achievements, challenges, perspectives. Journal of Environmental Policy \& Planning, 7(3), 175-184.

Healey, P. (1997). Collaborative planning: Shaping places in fragmented societies. Vancouver: UBC Press.

Hobbs, R. J., Higgs, E., \& Harris, J. A. (2009). Novel ecosystems: Implications for conservation and restoration. Trends in Ecology \& Evolution, 24(11), 599-605.

Holling, C. S. (1973). Resilience and stability of ecological systems. Annual Review of Ecology and Systematics, 4(1), 1-23.

Lampland, M., \& Star, S. L. (Eds.). (2009). Standards and their stories: How quantifying, classifying, and formalizing practices shape everyday life. Ithaca, NY: Cornell University Press.

Markolf, S. A., Chester, M. V., Eisenberg, D. A., Iwaniec, D. M., Davidson, C. I., Zimmerman, R., . . . Chang, H. (2018). Interdependent Infrastructure as Linked Social, Ecological, and Technological Systems (SETSs) to address lock-in and enhance resilience. Earth's Future. https://doi.org/10.1029/2018EF000926

Matsler, A. M. (2019). Making 'green' fit in a 'grey' accounting system: The institutional knowledge system challenges of valuing urban nature as infrastructural assets. Environmental Science \& Policy, 99, 160-168.

McPhillips, L. E., \& Matsler, A. M. (2018). Temporal evolution of green stormwater infrastructure strategies in three US cities. Frontiers in Built Environment, 4. https://doi.org/10.3389/fbuil.2018.00026

McPhillips, L. E., Matsler, A. M., Rosenzweig, B. R., \& Kim, Y. (2020). What is the role of green stormwater infrastructure in managing extreme precipitation events? Sustainable and Resilient Infrastructure. https://doi. org/10.1080/23789689.2020.1754625

Mell, I. C. (2013). Can you tell a green field from a cold steel rail? Examining the "green" of Green Infrastructure development. Local Environment, 18(2), 152-166.

Mell, I. C., \& Clement, S. (2019). Progressing green infrastructure planning: Understanding its scalar, temporal, geo-spatial and disciplinary evolution. Impact Assessment and Project Appraisal. https://doi.org/ 10.1080/14615517.2019.1617517

Miller, C. A., \& Munoz-Erickson, T. (2018). Designing knowledge. Tempe, AZ: Consortium for Science, Policy \& Outcomes.

Miller, T. R., Chester, M. V., \& Munoz-Erickson, T. (2018). Infrastructure for a stormy future: A more integrated and systemic approach is needed to ensure the nation's resilience in the face of a changing climate. Issues in Science and Technology, 2018(Winter), 46-58.

Munoz-Erickson, T. (2014). Co-productiom of knowledgeaction systems in urban sustainable governance: The KASA approach. Environmental Science \& Policy, 37, 182-191.

Odum, E. (1969). The strategy of ecosystem development. Science, 164(3877), 262-270.

Pinch, T. (2010). On making infrastructure visible: Putting the non-humans to rights. Cambridge Journal of Economics, 34(1), 77-89.

Ramsey, J., \& DiSalvo, A. (2018). Tree Canopy and potential in Portland, Oregon. Portland, OR: Portland Parks $\&$ Recreation.

Royal Society Science Policy Centre. (2014). Resilience to extreme weather (Policy Brief No. 02/14). London: Royal Society Science Policy Centre.

Star, S. L. (1999). The ethnography of infrastructure. American Behavioral Scientist, 43(3), 377-391.

Trust for Public Land. (2020). ParkScore Index: The most comprehensive evaluation of park access and quality in the 100 largest U.S. cities. TPL. Retrieved from https://www.tpl.org/parkscore

U.S. Census Bureau. (2017). Income in the past 12 months (In 2017 inflation-adjusted dollars), 2017: ACS 1-year estimates subject tables. U.S. Census Bureau. Retrieved from https://data.census.gov/ cedsci/all?q=median\%20income\%20estimates $\% 202017$

U.S. Census Bureau. (2019). Annual estimates of the resident population for incorporated places: April 1, 2010 to July 1, 2019. U.S. Census Bureau. Retrieved from https://www.census.gov/data/tables/timeseries/demo/popest/2010s-total-cities-andtowns.html 
Vogt, J. (2018). "Ships that pass in the night": Does scholarship on the social benefits of urban greening have a disciplinary crosstalk problem? Urban Forestry \& Urban Greening, 32, 195-199.

Watt, E., \& Marsalek, J. (2013). Critical review of the evolution of the design storm event concept. Canadian
Journal of Civil Engineering, 40(2), 105-113.

Wu, J., \& Loucks, O. (1995). From balance of nature to hierarchical patch dynamics: A paradigm shift in ecology. The Quarterly Review of Biology, 70(4), 439-466. Yin, R. K. (2014). Case study research: Design and methods (5th ed.). Los Angeles, CA: SAGE.

\section{About the Authors}

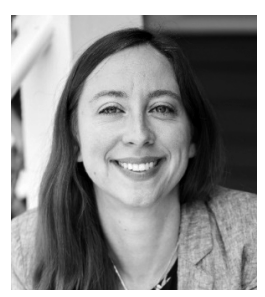

A. Marissa Matsler is a Postdoctoral Research Associate in the Department of Environmental Science and Technology at the University of Maryland, College Park. She is an interdisciplinarian with a research focus on multi-perspective analysis of urban environmental governance and green infrastructure policy utilizing mixed methods approaches.

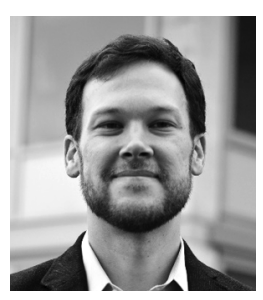

Thaddeus R. Miller is an Associate Professor in the new School of Public Policy at the University of Massachusetts Amherst. He collaborates with interdisciplinary teams of researchers and practitioners to enable cities to leverage science and technology to meet policy goals and community needs. His recent book, Reconstructing Sustainability Science: Knowledge and Action for a Sustainable Future, examines how scientists can navigate epistemic and normative tensions to link knowledge to social action.

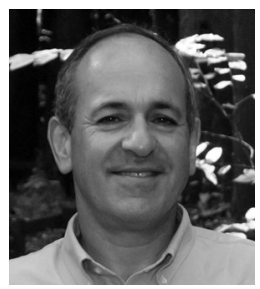

Peter M. Groffman is a Professor at the City University of New York Advanced Science Research Center and Brooklyn College Department of Earth and Environmental Sciences, and a Senior Research Fellow at the Cary Institute of Ecosystem Studies. He has research interests in ecosystem, soil, landscape and microbial ecology, with a focus on carbon and nitrogen dynamics in forests and urban ecosystems. 